\title{
Infectious disease management: Lessons from Cuba
}

\author{
Noni E MacDonald MD MSc FRCPC ${ }^{1}$, Beth Halperin RN MN ${ }^{1}$, Enrique Beldarrain Chaple $\mathrm{MD}^{2}$, \\ Jeff Scott MB CM MHSC MHSA FRCPC ${ }^{3}$, John M Kirk PhD ${ }^{4}$
}

$\mathrm{O}$ ver the past decade in Canada, infectious disease outbreaks have repeatedly been in the public spotlight. The Escherichia coli outbreak in Walkerton, Ontario (1), the severe acute respiratory syndrome outbreak in Toronto, Ontario (2) and the Clostridium difficile hospital outbreak in Montreal, Quebec (3), have cost lives, grabbed headlines and stressed local health care systems. Each outbreak raised questions about our ability to prevent outbreaks, detect outbreaks early, and respond efficiently and effectively to infectious disease crises; these outbreaks also highlighted gaps in Canada's preparedness for managing major infectious disease problems when multiple jurisdictions are involved (4). Canada's poor track record of tuberculosis control in the north (5) raises the concern that this problem is not limited to crisis situations, but rather has deeper implications for the management of infectious diseases in Canada.

A 2004 World Health Organization (WHO) report, entitled 'World Report on Knowledge for Better Health: Strengthening Health Systems', stresses the importance of being open to new ideas and approaches for translating health care knowledge into action (6). The following observation from the WHO report is particularly apt when applied to many Canadian infectious disease management problems (6):

"The knowledge that an intervention works is only half the equation of improved health. What is standing in the way of improved health is the knowledge about how to effectively implement and use the interventions".

Knowledge, expertise and money are often not the limiting factors.

Industrialized countries, including Canada, tend to be narrow in their selection of approaches to address health care problems (including those in infectious diseases), looking no further than to each other. Hence, each country uses similar research strategies, paradigms and sources of evidence, convinced that these approaches are best. Outcomes and evidence from developing countries are largely ignored or considered irrelevant, despite their successful track record in managing infectious diseases in the face of sparse resources.

Cuba, a relatively poor and small country (population 11.2 million), has managed to bring about remarkable achievements in health in the past 30 years despite difficult fiscal restraints and limited resources (Table 1) (7-10).

The scope of Cuba's success has been validated through the authors' study of Cuba over many years (JMK: Over 65 visits to Cuba since 1976, written or coedited 13 books on Cuba; EBC: Cuban physician/epidemiologist/medical historian living and working in Cuba; JMK, NEM, BH and EBC: Personal observation of the Cuban health care system). To illustrate this success, we chose to compare Cuban data with data from the United States and Canada (because these were readily available) to clearly show what Cuba has been able to achieve.

The experience of the United States has shown that more money for health care does not translate automatically into better health. Indeed, while the United States has the highest health spending per capita (7), it does not have the healthiest population in the world (Table 1) (7-9). In contrast, Cuba, with much fewer resources, has managed to bring about the elimination of polio and good control of tuberculosis, and can claim the lowest rate of HIV in Latin America $0.05 \%$ in 2004 according to the Joint United Nations Programme on HIV/AIDS (UNAIDS) [10]). Cuba also has a better infant mortality rate than the United States as well as the same life expectancy at birth (8). Cuba's health achievements have been attained with only a fraction of the resources available in the United States and in other Organisation for Economic Co-operation and Development (OECD) countries. According to the World Bank (7), Cuba spends $7.5 \%$ of its gross domestic product on health expenditure, compared with $9.6 \%$ in Canada, $14.6 \%$ in the US, and the OECD average of $8.6 \%$ in 2003 (Table 1) $(7,9)$. Of note, the overall annual per capita income of the Cuban population is only $\$ 1,170$ compared with $\$ 28,390$ in Canada and $\$ 41,400$ in the United States in 2004 (8).

${ }^{1}$ Dalhousie University, Canadian Centre for Vaccinology, Halifax, Nova Scotia; ${ }^{2}$ National Center for Medical Sciences Information, Havana,

Cuba; ${ }^{3}$ Canadian Centre for Vaccinology; ${ }^{4}$ Dalhousie University, Halifax, Nova Scotia

Correspondence: Dr Noni E MacDonald, Division of Pediatric Infectious Diseases, IWK Health Centre, 5850/5980 University Avenue,

PO Box 9700, Halifax, Nova Scotia B3K 6R8. E-mail noni.macdonald@dal.ca

Received for publication March 8, 2006. Accepted for publication June 8, 2006 
TABLE 1

Basic indicators at a glance: The United Nations Children's Fund (UNICEF), Organisation for Economic Co-operation and Development (OECD) and the World Bank

\begin{tabular}{lccccc}
\hline Indicator & Cuba & Canada & $\begin{array}{c}\text { United } \\
\text { States }\end{array}$ & Japan & $\begin{array}{c}\text { United } \\
\text { Kingdom }\end{array}$ \\
\hline $\begin{array}{c}\text { Total population, } \\
\text { 2004 (thousands) }\end{array}$ & 11,245 & 31,958 & 295,410 & 127,923 & 59,479 \\
$\begin{array}{c}\text { GDP spent on } \\
\text { health, 2003 (\%) }\end{array}$ & 7.5 & 9.6 & 14.6 & 7.9 & 7.7 \\
$\begin{array}{l}\text { GNI per capita*, 2004 } \\
\text { Infant mortality rate } \\
\quad \text { (under 1 year), 1960 }\end{array}$ & 39,170 & $\$ 28,390$ & $\$ 41,400$ & $\$ 37,180$ & $\$ 33,940$ \\
$\begin{array}{c}\text { Infant mortality rate } \\
\quad \text { under 1 year), 2004 }\end{array}$ & 6 & 5 & 26 & 31 & 23 \\
$\begin{array}{c}\text { Under 5 years mortality } \\
\text { rate, 1960 }\end{array}$ & 54 & 33 & 30 & 40 & 27 \\
$\begin{array}{c}\text { Under 5 years mortality } \\
\text { rate, 2004 }\end{array}$ & 7 & 6 & 8 & 4 & 6 \\
$\begin{array}{c}\text { Life expectancy at } \\
\text { birth, 2004 (years) }\end{array}$ & 78 & 80 & 78 & 82 & 79 \\
\hline
\end{tabular}

${ }^{*}$ Currency is expressed in United States dollars. GDP Gross domestic product; GNI Gross national income. Data from references 7 to 9

TABLE 2

Number of health care professionals per 10,000 population in 2002: Canada versus Cuba

\begin{tabular}{lcc}
\hline Profession & Canada & Cuba \\
\hline Physicians & $21.0 / 10,000$ & $54.6 / 10,000$ \\
Nurses & $98.0 / 10,000$ & $69.1 / 10,000$ \\
Dentists & $5.7 / 10,000$ & $8.7 / 10,000$ \\
\hline
\end{tabular}

Data from references 9,11 and 12

\section{WHAT ARE SOME OF THE FACTORS THAT APPEAR TO HAVE BEEN IMPORTANT FOR THIS CUBAN SUCCESS IN HEALTH?}

Despite overwhelming economic difficulties, the government of Cuba has maintained its commitment to a comprehensive system of health care, oriented to primary care and prevention (11). The Cuban philosophy of health care is simple: provide high levels of medical support at no cost to the patient for the entire population, and pursue a resolutely preventive approach to health care - especially in the area of infectious diseases (12). Equity of access, attention to the most relevant health issues and emphasis on cost effectiveness are fundamental to the success of the Cuban health care system. Access to quality health care, including promotional, preventive, curative and rehabilitative services, is seen by both the government and the public as one of the two crown jewels of the country, the other being access to quality education.

Alongside this careful attention to health care and education, Cuba has also focused its attention on other major determinants of health through subsidized quality housing; low unemployment rates and widespread job-creation programs; social security and retirement benefits; a nationwide (and heavily subsidized) day care and early childhood education program; sanitation efforts; nutrition support via the Cuban ration card system, which provides all Cubans a guaranteed amount of affordable food regardless of wealth or location; and community involvement in all population-based prevention strategies (11).

Another major difference between Canada and Cuba is in the area of intersectoral relationships between populationbased organizations (which bring together unionized workers, neighbours, peasants, women, professionals and students), government bodies and ministries (13). The Committees to Defend the Revolution and the Cuban Women's Federation are particularly important. The Committees to Defend the Revolution bring the neighbours on a city block together almost every month to analyze legislation and government policies, discuss neighbourhood problems and shortages, and plan how best to use collective resources (everything from recycling bottles to cleaning the streets). A key role has been their duty to share information, including news on personal and public health issues. The impact of this integration of both medical and nonmedical aspects of health can be observed in Cayo Hueso, Cuba, where this ecosystem approach to health was used to improve the quality of life and health outcomes (14).

With respect to the formal health care system, the Cuban government has concentrated sparse resources largely in primary health care, with 32,000 family doctors (more than $50 \%$ of all doctors) working alongside 32,000 nurses in the community to support the emphasis on prevention, early diagnosis, prompt care and timely rehabilitation. As shown in Table 2, there are sharp contrasts between the numbers of physicians and nurses per capita in Cuba and Canada $(9,15,16)$. Cuba has one doctor for approximately every 200 people compared with Canada, where the ratio is one per 476.

Medical education consists of a six-year medical curriculum that parallels the Canadian program, from which students graduate as 'general comprehensive physicians' (also known as general practitioners) (17). There is much emphasis on determinants of health, epidemiology and preventive care. Following graduation, there are two years of mandatory family medicine residency training. Postgraduate opportunities for physicians are available for those who wish to pursue further specialty training. Although it is difficult to obtain an objective measure of the quality of the Cuban medical education model, Cuba's outstanding achievements in health indicators, as outlined in Table 1, attest to the success of this medical education strategy.

The 'Family Doctor and Nurse' program was first initiated in a Havana neighbourhood in 1984, and has expanded to become the norm over the past 21 years (17). Preventive health care and close doctor/nurse-patient-community relations are at the heart of this strategy, which puts emphasis on maternal and child health, chronic noncommunicable diseases, communicable diseases, care of the elderly, and Continuous Assessment and Risk Evaluation (CARE Program) (17).

In the Family Doctor and Nurse model, the health care team lives in the community and meets with each patient in their catchment area at least twice a year, maintaining detailed records, using a checklist format, and doing ongoing risk evaluation accompanied by personal patient intervention and education programs (CARE Program). Records, including those on immunization, are meticulous (NEM, BH and JMK, personal communication).

Each team provides care for 700 to 800 people, or approximately 120 families (12,17). The Family Doctor and Nurse team are also integrated into a multidisciplinary polyclinic 
team with the community obstetrician, geriatrician, psychiatrist, social worker and statistician (18). The polyclinics focus on providing basic emergency services, specialist clinics and rehabilitation services, and they have a strong public health focus to ensure that preventive measures, such as routine immunization; testing, treatment and follow-up for tuberculosis and HIV; and local and home mosquito control to decrease the risk of dengue, are all performed expeditiously.

Active exchange of epidemiological data among the local Family Doctor and Nurse team, the polyclinic and the national health care system (Ministerio de Salud Pública de Cuba) allows for regular evaluation of current programs, updates on communicable diseases and identification of target areas in need of specific interventions at the local level, all in a timely fashion. The public health links between the national level and the community and local levels are therefore tight, and dialogue is bidirectional.

By living in the community where they work, the Family Doctor and Nurse teams are well placed to detect risk factors, medical difficulties and infectious disease outbreaks early. They provide leadership in the community in the areas of environmental and public health. They are expected to control or report any environmental concerns noted in the community and to work in disease prevention $(12,17)$. Their activities range from ensuring garbage is handled correctly, to supervising insecticide brigades seeking to kill mosquito larvae to prevent malaria and dengue fever, to tracking down those who have missed an immunization or a pap smear test.

An example of the benefit of such a linked system is seen in the way in which patients are managed following discharge from hospital. In contrast with Canada, the norm in Cuba is that the Family Doctor and Nurse team is actively involved with both in-hospital and community management of their patients, with all discharged patients in Cuba receiving daily home visits to ensure a smooth transition of care from hospital to community. The team is well placed and well connected to detect and report on nosocomial infections.

The Family Doctor and Nurse program and other programs focused on the nonmedical determinants of health have all contributed to outstanding health outcomes for a developing country with very modest resources. Infant mortality rates and under-five mortality rates have declined from rates much higher than those of industrialized countries in the 1960s (39 per 1000 under one year of age) to rates on par with OECD countries in 2004 (Table 1) (9). In addition, there has been a significant decrease in hospital outpatient visits, which fell by almost 50\% between 1980 and 2000, and in the rate of hospitalizations (from 15.1 per 1000 inhabitants in 1984 to 10.8 per 1000 inhabitants in 2003) accompanied by a $20 \%$ increase in patient visits at the primary care level (17).

The success of Cuba's immunization program is particularly worth noting. Over 95\% of Cuban children are immunized against 13 vaccine-preventable diseases $(17,19)$, a rate that is better than that seen in many OECD countries. Polio, measles, mumps, rubella, diphtheria and tetanus have disappeared $(15,19)$, a remarkable feat given the country's limited resources. These outcomes led the Pugwash Conference to nominate Cuba's National Immunization Program for the Gates Award for Global Health in 2001 (20). Furthermore, in the spirit of 'people before profit', Cuba's political priority has been to develop its own resources to meet its health needs (21), including those for immunization. Hence, Cuba has developed a strong vaccine manufacturing program using its own domestic capacities, thus ensuring security of supply, which is a goal of the Canadian National Immunization Strategy (22) that has yet to be achieved by Canada.

Cuba's vector control program provides another striking example of how the country effectively mobilizes in the face of a public health crisis (23). Coordinated efforts by entire communities, relevant political legislation and improvements to the public health infrastructure all contributed to the success of their campaign against Aedes aegypti, to control dengue disease.

In addition to Cuba's remarkable success in health indexes related to immunization and infectious disease, it is important to note other advances that have been made in disease prevention and control. For example, Cuba has made considerable progress in reducing the mortality burden from cardiovascular disease, with levels of control of hypertension among the best in the world (24).

Other developing countries are also reaping benefits from Cuban health care expertise through Cuban medical missions in a number of developing countries in Africa and Latin America; by provision of free medical education for students from these countries; by adaptation of the Cuban model locally in these countries to improve health; and through the provision of low-cost, WHO-prequalified Cuban vaccines (25-27). Developing countries are also interested in how a relatively poor country like Cuba has been able to achieve major successes in health biotechnology (21).

Cuba's outstanding achievements in health care outcomes should inspire any country considering strategies for health care reform. Cuba's adherence to the three underlying principles of equity, integration of public health services, and the imaginative harnessing of human resources in a collaborative manner has been key to its success. In particular, in the current global climate of emerging infectious diseases, the world would be remiss not to heed Cuba's ecosystem health approach to potential health crises.

While some components of the Cuban model and those in other developing countries may be specific to local context and resist transplantation from their distinctive cultural and political environment to ours, we should not be dismissive about what we can learn from developing countries' application of the four WHO critical Health Compass criteria for success - namely, relevance, quality, equity and costeffectiveness (28).

The excellent health outcome results in Cuba at modest cost begs a number of questions: can similar successes be obtained in Canada if some Cuban health care strategies especially those related to infectious disease control noted above - are adapted, particularly for our marginalized and vulnerable populations? Could we, too, reap significant health benefits by redressing the balance and tightening the links between public health and primary and acute care medicine in our country as was done in Cuba?

We believe there is much to be learned about quality, costeffective health care from developing countries. It is time to expand our vision to embrace alternative models of health care that have met with such success. By considering lessons from Cuba, within the Canadian context, we may put ourselves in a better position to address our own health care needs, particularly those related to infectious diseases. 


\section{REFERENCES}

1. Hrudey SE, Hrudey EJ. Walkerton and North Battleford - key lessons for public health professionals. Can J Public Health 2002;93:332-3.

2. Hawryluck L, Lapinsky SE, Stewart TE. Clinical review: SARS lessons in disaster management. Crit Care 2005;9:384-9.

3. Loo VG, Poirier L, Miller MA, et al. A predominantly clonal multiinstitutional outbreak of Clostridium difficile-associated diarrhea with high morbidity and mortality. N Engl J Med 2005;353:2442-9.

4. Public Health Agency of Canada. Learning from SARS - Renewal of Public Health in Canada. <www.phac-aspc.gc.ca/publicat/ sars-sras/naylor $>$ (Version current at July 20, 2006).

5. Public Health Agency of Canada. Tuberculosis in Canada 2002. $<$ www.phac-aspc.gc.ca/publicat/tbcan02> (Version current at July 20, 2006).

6. World Health Organization. World Report on Knowledge for Better Health: Strengthening Health Systems. <www.who.int/rpc/meetings/ en/world_report_on_knowledge_for_better_health2.pdf $>$ (Version current at July 20, 2006).

7. The World Bank. HNP at a glance: Cuba, Canada, Japan, United Kingdom, United States. <http://devdata.worldbank.org/ hnpstats/cd1.asp> (Version current at July 20, 2006).

8. UNICEF. Statistics at a glance.

Cuba <www.unicef.org/infobycountry/cuba_statistics.html >; Canada $<$ www.unicef.org/infobycountry/canada_statistics.html >; USA $<$ www.unicef.org/infobycountry/usa_statistics.html>; Japan $<$ www.unicef.org/infobycountry/japan_statistics.html >; United Kingdom < www.unicef.org/infobycountry/uk_statistics.html > (Version current at July 20, 2006).

9. OECD health data 2005: Statistics and indicators for 30 countries. <www.oecd.org/document/30/0,2340,en_2649_34631_12968734_1_1 _1_1,00.html >; Canada <www.oecd.org/dataoecd/16/9/ 34969633.pdf>; United States <www.oecd.org/dataoecd/15/23/ 34970246.pdf>; Japan <www.oecd.org/dataoecd/16/4/34970111.pdf>; United Kingdom < www.oecd.org/dataoecd/15/24/34970234.pdf> (Version current at July 20, 2006).

10. UNAIDS 2004 Report on the global AIDS epidemic. <www.unaids.org/bangkok2004/report.html> (Version current at July 20, 2006).

11. Spiegel JM, Yassi A. Lessons from the margins of globalization: Appreciating the Cuban health paradox. J Public Health Policy 2004;25:85-110.

12. Cuban Medical Literature: Origins of Primary Health Care in Cuba. $<$ www.medicc.org/medicc_review/1104/pages/cuban_medical_ literature.html> (Version current at July 20, 2006).

13. Uriarte M. Cuba. Social policy at the crossroads: Maintaining priorities, transforming practice. <www.oxfamamerica.org/newsandpublications/ publications/research_reports/art3670.html/pdfs/social_policy.pdf > (pages 38 to 57) (Version current at July 20, 2006).
14. Spiegel J, Bonet M, Yassi A, Tate RB, Concepcion M, Canizares M. Evaluating the effectiveness of a multi-component intervention to improve health in an inner-city Havana community. Int J Occup Environ Health 2003;9:118-27.

15. Pan American Health Organization. Cuba: Country Health Profile. $<$ www.paho.org/English/SHA/prflcub.htm> (Version current at July 20, 2006).

16. Canadian Institute for Health Information. Health Personnel Trends in Canada, 1993 to 2002. < http://secure.cihi.ca/cihiweb/ dispPage.jsp?cw_page $=P G \_69 \_E \& c w \_t o p i c=69 \& c w \_r e l==A R \_21$ E\#download $>$ (Version current at July 20, 2006).

17. Labrador CP, Soberat FS. 20 years of family medicine in Cuba. <www.medicc.org/medicc_review/1104/pages/spotlight.html> (Version current at July 20, 2006).

18. Díaz Novás J, Fernández Sacasas JA. From Municipal Polyclinics to Family Doctor-and-Nurse Teams. <www.medicc.org/Medicc\%20 Review/II/primary/poly.html> (Version current at July 20, 2006).

19. WHO/UNICEF Review of National Immunization Coverage. $<$ www.who.int/immunization_monitoring/data/cuba.pdf $>$ (Version current at July 26, 2006).

20. Pugwash online. The Gates Award for Global Health. $<$ www.pugwash.org/reports/ees/ees8c.htm> (Version current at July 20, 2006).

21. Thorsteinsdottir H, Saenz TW, Quach U, Daar AS, Singer PA. Cuba - innovation through synergy. Nat Biotechnol 2004;22(Suppl):DC19-24.

22. National Immunization Strategy: Final report 2003. <www.phac-aspc.gc.ca/publicat/nat_immunization_03/b4.html> (Version current at July 20, 2006).

23. Spiegel J, Yassi A, Tate R. Dengue in Cuba: Mobilisation against Aedes aegypti. Lancet Infect Dis 2002;2:207-8.

24. Cooper RS, Ordunez P, Iraola Ferrer MD, Munoz JL, Espinosa-Brito A. Cardiovascular disease and associated risk factors in Cuba: Prospects for prevention and control. Am J Public Health 2006;96:94-101.

25. Frank M, Reed GA. Doctors for the (developing) world. <www.medicc.org/medicc_review/0305/pages/spotlight.html> (Version current at July 20, 2006).

26. Mullan F. Affirmative action, Cuban style. N Engl J Med 2004;351:2680-2.

27. Clemens J, Jodar L. Introducing new vaccines into developing countries: Obstacles, opportunities and complexities. Nat Med 2005;11(Suppl 4):S12-5.

28. World Health Organization. Challenges and opportunities for partnership in health development: A working paper. $<$ www.who.int/entity/hrh/documents/en/TUFH_challenges.pdf> (Version current at July 20, 2006). 


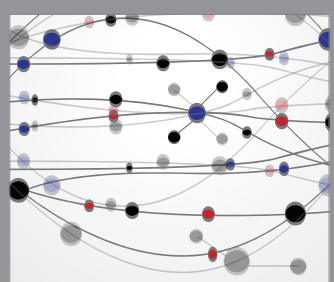

The Scientific World Journal
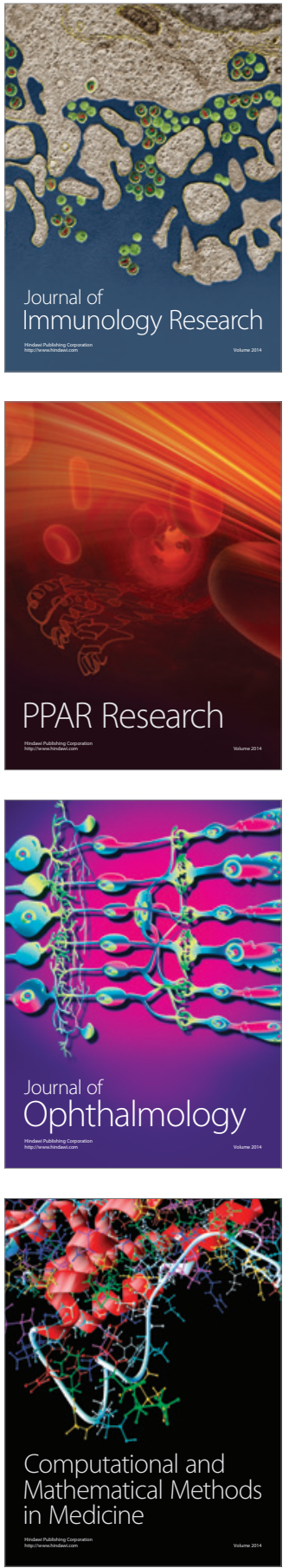

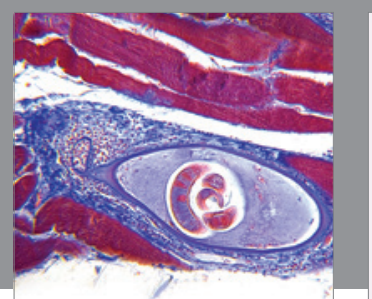

Gastroenterology Research and Practice

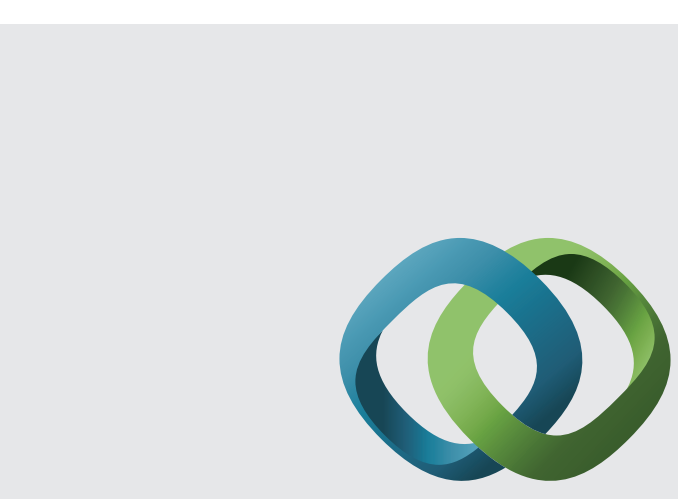

\section{Hindawi}

Submit your manuscripts at

http://www.hindawi.com
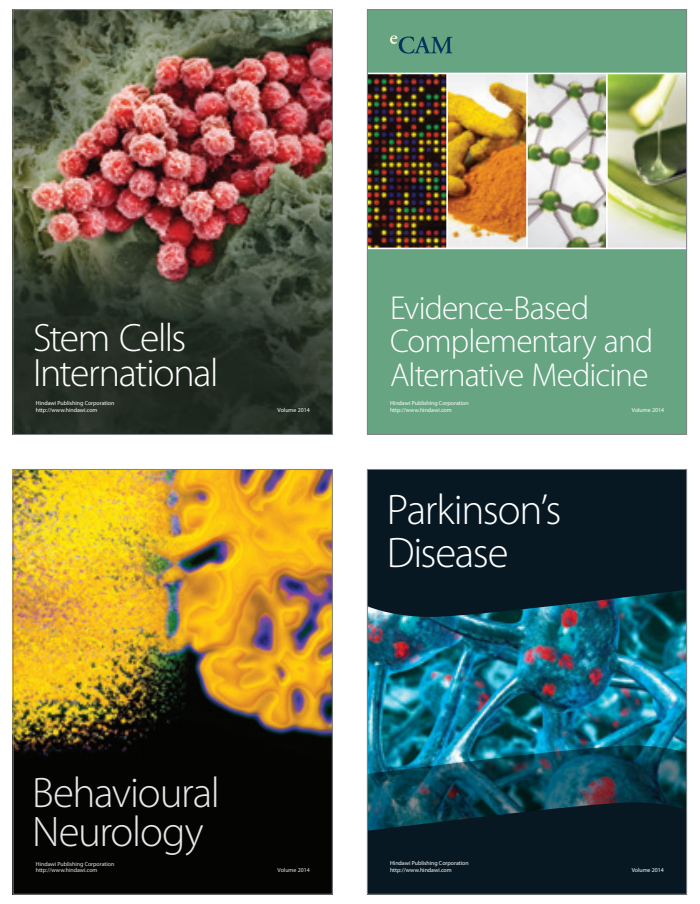
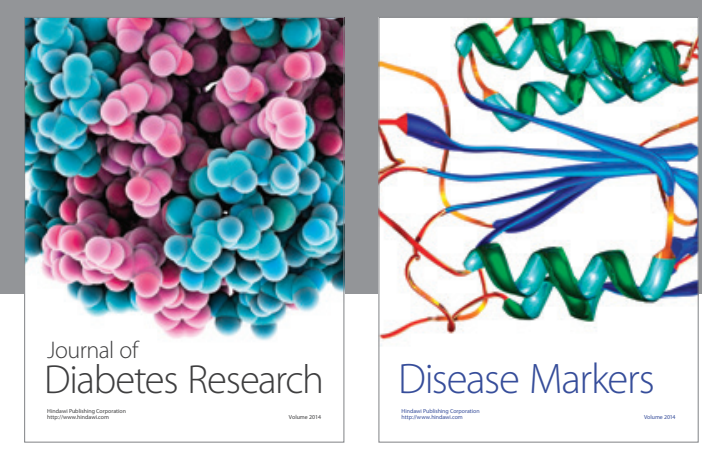

Disease Markers
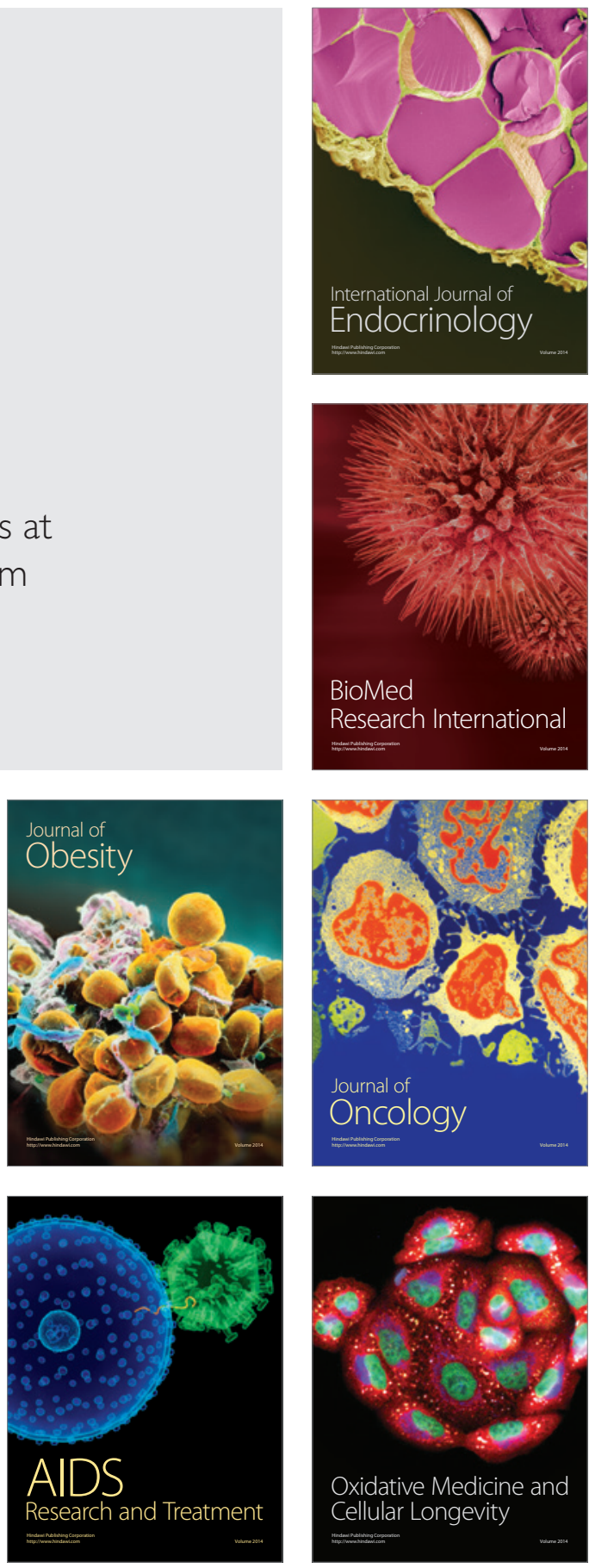